\title{
Diversificação da Matriz de Energias Renováveis no Brasil: O Desenvolvimento das Novas Fontes de 2010 a 2016
}

Diversification of the Renewable Energy Matrix in Brazil: The Development of the New Sources from 2010 to 2016

\author{
Renan Teófilo Ferraz ${ }^{1}$ \\ Alcides Codeceira ${ }^{1}$ \\ ${ }^{1}$ Escola Politécnica de Pernambuco, Universidade de Pernambuco, Recife, Brasil, \\ E-mail do autor principal: Renan Teófilorenan.teofilo@gmail.com
}

\section{Resumo}

É indubitável e bastante presente na literatura o fato de que o Brasil precisa diversificar sua matriz de energia renovável. Os Biocombustíveis, a energia eólica e energia solar receberam neste estudo toda a tenção como fontes a serem exploradas em prol desta diversificação. Os principais fatores para esta necessidade estão abrindo o panorama apresentado neste artigo, sobre a evolução da diversificação da matriz energética no Brasil nos anos de 2010 a 2016, com base no histórico evolutivo da produção das novas fontes a serem mais exploradas com o propósito desta diversificação. Por fim, é levantado o que foi feito e quais barreiras existem neste processo de diversificação que ainda há bastante o que evoluir.

Palavras-Chave: diversificação energética; energia renovável; novas fontes renováveis.

\begin{abstract}
The fact that Brazil needs to diversify its renewable energy matrix is undoubtedly and present in the literature. Biofuels, wind energy and solar energy in this study received all the attention as sources to be explored in favor of this diversification. The main factors for this need are opening the scenario presented in this article on the evolution of the diversification of the energy matrix in Brazil in the years 2010 to 2016, based on the evolutionary history of the production of the new sources to be more exploited for the purpose of this diversification. Finally, what has been done is raised and what barriers exist in this process of diversification that there is still much to evolve.
\end{abstract}

Key-words: energy diversification; renewable energy; new renewable sources. 


\section{As necessidades para a diversificação da Matriz de Energias Renováveis no Brasil}

Embora o Brasil seja considerado um país à frente da média global em matéria da matriz de geração limpa, este sucesso se deve à sua participação em geração de energia hidroelétrica, que em julho de 2017, esta matriz correspondeu a $64,6 \%$ da capacidade instalada no país, com 1.306 usinas [1].

Historicamente, o Brasil se beneficiou de seus recursos naturais para a geração de tal energia, sendo amplamente utilizada e, consequentemente, adquirindo aprimoramento tecnológico neste segmento.

Contudo, a expansão das hidráulicas enfrenta progressivamente maiores custos e restrições [2], como o exemplo apontado por Fernandez e Pereira [3], que se tratando da forma como foi adotada a Tarifa Social, a geração hidráulica de energia incorre em custos de sustentabilidade para os sistemas hídricos, ao impor restrições de ordem técnica. As tarifas impostas não são suficientes para cobrir custos e dar margem de lucro [4].

Há também o fato de que uma hidrelétrica leva cerca de seis anos para ficar pronta, uma eólica, por exemplo, leva 1 ano e meio em média. Isto, sem falar que basta as condições meteorológicas afetarem negativamente a hidrografia do Brasil para ocasionar uma queda da participação da matriz renovável. Nos períodos de seca, a energia gerada pelas hidrelétricas fica mais escassa e, consequentemente, mais cara.

Além disto, o Brasil está comprometido com a $21^{a}$ Conferência das Partes (a COP 21) no alinhamento com os outros países membros em reduzir as emissões dos gases de efeito estufa, envolvidos em determinados processos de produção de energia, e, dentre outros, expandir o consumo de biocombustíveis e aumentar a participação de novas energias renováveis na matriz energética.

Deste modo, há uma necessidade do Brasil em diversificar sua matriz energética, aproveitando ainda, as oportunidades das novas fontes de energias renováveis.

Para efeitos ilustrativos, na imagem a seguir está a participação percentual das fontes de energia na matriz energética no Brasil, em termos de volume de produção, segundo os dados do relatório do Balanço Energético Nacional de 2017, tendo o ano de 2016 como ano base:

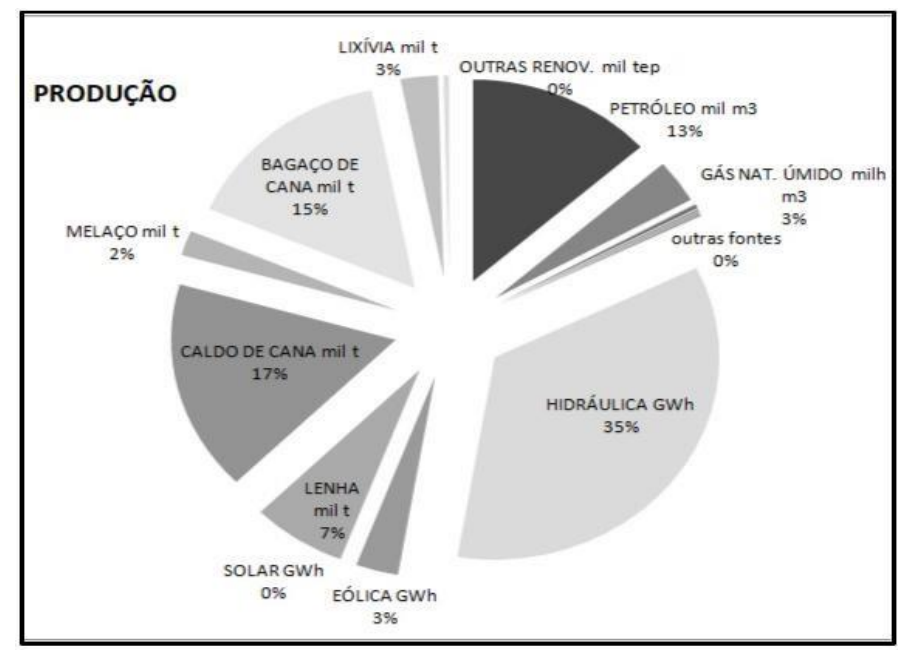

Figura 1: Matriz de produção energética no Brasil 2017

(Ano base 2016) [5]

\section{As novas fontes de energias renováveis no Brasil}

No caso brasileiro, as novas fontes de energia que deverão ser exploradas são:

\subsection{Biocombustíveis}

É o combustível produzido a partir de fontes de energia de origem biológica e não fóssil, nos estados sólido, líquido e gasoso [6]. A sua produção, leva a um maior aproveitamento da biomassa, transformando os rejeitos dos processos em recurso para a produção de energia, além de contribuir para a diminuição das emissões dos gases de efeito estufa. Os biocombustíveis considerados são:

- Etanol de segunda geração (etanol 2G ou lignocelulósico). Também conhecido por Bioetanol, é produzido a partir do bagaço de cana-de-açúcar;

- Biodiesel. É fabricado a partir de fontes vegetais ou animais como óleo de soja, gordura animal, óleo de algodão, etc. 


\subsection{Eólica}

É o aproveitamento e a transformação da energia somente do vento em energia mecânica ou eletricidade. São transformadas, geralmente a partir de velas, turbinas e moinhos de vento.

\subsection{Solar}

Uma energia que provém do sol, utilizada por diferentes tecnologias, seja aproveitando o seu calor para aquecimento solar, sua luminosidade para energia fotovoltaica, heliotérmica, a fotossíntese artificial ou a arquitetura solar.

\section{Um panorama da evolução produtiva das novas fontes de energia renovável no Brasil de 2010 a 2016}

\subsection{0}

O montante de Biodiesel produzido no país atingiu 2.397.272 $\mathrm{m}^{3}$, ampliando sua disponibilização no mercado interno. A principal matéria prima foi o óleo de soja $(82,2 \%)$ seguido do sebo bovino $(13,0 \%)$ [7].

A capacidade instalada no Brasil de usinas de biomassa era de 356, com capacidade para 6.227.660 $\mathrm{kW}$, representando $5,82 \%$ da capacidade total de energia no país[7]. A produção de etanol atingiu a marca de $27.962 .558 \mathrm{~m}^{3}$. Deste total, o álcool hidratado representou $71 \%$ e o restante da produção foi do álcool anidro, que é misturado à gasolina A para formar a gasolina C [7].

A produção de eletricidade a partir da fonte eólica alcançou 2.176,6 GWh em 2010, o parque eólico nacional alcançou 928 MW ao final de 2010, em decorrência da inauguração de catorze parques eólicos [7].

Em janeiro de 2010, havia apenas 1 usina com capacidade de $20 \mathrm{KW}$ no Brasil. Isto representava menos de $0,01 \%$ da capacidade instalada das matrizes energéticas no país [8].

\subsection{1}

A geração de energia a partir de biomassa (usado para fabricação de biocombustíveis), atingiu em 2011 $6,6 \%$ de toda a matriz energética do Brasil [8], tendo 391 usinas instaladas com capacidade total de 7.888 MW [10].

Com relação ao ano anterior, houve também um aumento de $24,3 \%$ da geração eólica em 2011, ajudando no aumento da participação dos renováveis na matriz energética nacional, atingindo o volume de produção de $2.705 \mathrm{GWh}$ [9], porém, este aumento se deu devido a importação dessa energia, já que a capacidade instalada em janeiro de 2011 era de 929 MW, com 51 usinas no país. No início de 2011, a produção interna de energia eólica foi menor do que a do mesmo período do ano anterior em 13,9\% [10].

Desde janeiro do ano anterior, foram adicionadas à matriz energética 3 novas usinas solares, mas ainda correspondia a menos de $0,01 \%$ da Mariz de toda a capacidade de energia instalada no Brasil [10].

\subsection{2}

As usinas de biocombustíveis, produziram 286 GWh de energia em janeiro de 2012, com 429 usinas de biomassa com capacidade instalada para gerar 8.993 MW [11], passando a produzir no ano todo um total de $4.767 \mathrm{GWh}$ [12]. O montante de biodiesel produzido alcançou $2.717 .483 \mathrm{~m}^{3}$, havendo um aumento de $1,7 \%$ com relação ao ano anterior e continua como principal matéria prima o óleo de soja e o sebo bovino, representando juntos $84,3 \%$ de toda a matéria prima para a produção do biodiesel. Houve também um acréscimo na produção de etanol devido ao crescimento da produção de cana-de-açúcar [13].

O ano de 2012 foi bem representativo para a geração de energia eólica no Brasil. No primeiro mês do ano já havia produzido 264 GWh de energia, correspondendo a $0,6 \%$ da produção nacional, com 73 usinas e capacidade instalada de $1.471 \mathrm{MW}$ [13]. Fechou o ano produzindo 4.415 GWh de energia, correspondendo a $0,9 \%$ da produção de energia do Brasil, com 84 usinas e capacidade instalada de 1.886 MW [14]. Se somado com a importação dessa energia, foi produzido no Brasil 5.050 GWh, um aumento de $86,7 \%$ com relação ao ano anterior [15]. 
Em janeiro já haviam 8 usinas solares, com capacidade instalada para $1 \mathrm{MW}$ [13]. Até o final do ano 3 novas usinas solares foram adicionadas à matriz de energia elétrica, o que deu uma capacidade instalada de $8 \mathrm{MW}$ [14].

\subsection{3}

Ainda como matéria prima principal o óleo de soja e o sebo bovino, o biodiesel produzido no Brasil no ano de 2013 alcançou o volume de $2.917 .488 \mathrm{~m}^{3}$, aumentando em $7,4 \%$ em relação ao ano anterior. Com o aumento da produção de cana-de-açúcar, a produção de etanol cresceu $17,6 \%$ com relação ao ano anterior, retirando uma margem da produção de açúcar, que caiu $3,1 \%$ neste ano [16].

A produção de eletricidade a partir da fonte eólica cresceu 30,3\% em 2013, alcançando 6.579 GWh [16] e expandiu a capacidade instalada para geração em $16,7 \%$ [17] no Brasil, com o potencial para 2.202 MW e com 108 usinas.

A capacidade instalada, fiscalizada pela ANEEL, para a produção de energia elétrica a partir da fonte solar, em dezembro de 2013 foi reduzida, com relação ao ano anterior, correspondendo a $5 \mathrm{MW}$, mesmo com 45 usinas no país [17].

\section{$3.5 \quad 2014$}

Houve um aumento de $17,2 \%$ da produção do biodiesel em 2014, com relação ao ano anterior, chagando a $3.419 .838 \mathrm{~m}^{3}$, tendo como matéria prima principal os mesmos dos anos anteriores. Apesar do montante produzido de cana-de-açúcar ter sido menor do que o do ano anterior, a produção do etanol foi $3,3 \%$ maior este ano, com relação ao ano anterior [18].
A produção de energia eólica alcançou $12.210 \mathrm{GWh}$ em 2014, correspondendo a um aumento de $85,6 \%$ em relação ao ano anterior. O parque eólico nacional cresceu $2.686 \mathrm{MW}$, alcançando $4.888 \mathrm{MW}$ ao final de 2014, com a potência instalada expandida em $122 \%$ [18]. Isto corresponde a $3,6 \%$ da capacidade da produção de energia do país [19].

Em compensação pela diminuição da produção de energia solar do ano anterior, houve um crescimento substancial na matriz solar em 2014. No final do ano, haviam 311 usinas de energia solar no país, com capacidade instalada de $15 \mathrm{MW}$. Isto representou uma evolução de $201,8 \%$ em relação ao ano anterior [19]. Este ano superou até no número de usinas da fonte eólica.

\section{$3.6 \quad 2015$}

Com exceção do Álcool Anidro, a produção dos demais biocombustíveis teve seu volume aumentado neste ano, com relação ao ano anterior, embora sua parcela de transformação em energia foi menor.

Houve um salto na produção de energia eólica com relação ao ano anterior, passando de $12.210 \mathrm{GWh}$ para 21.626 GWh em 2015 [20].

Outro salto se deu na energia solar, onde a capacidade instalada passou de 15 MW em 2014 para 21 MW em 2015 [21].

Tabela 1: Produção de Energia de algumas fontes Renováveis no Brasil de 2010 a 2016

\begin{tabular}{|c|c|c|c|c|c|c|c|}
\hline BIOCOMBUSTÍVEIS & 2010 & 2011 & 2012 & 2013 & 2014 & 2015 & 2016 \\
\hline \multicolumn{8}{|l|}{$\begin{array}{l}\text { BIOCOMBUSTleo Diesel Total } \\
\text { ÓlS }\end{array}$} \\
\hline Produção $\left(10^{3} \mathrm{~m}^{3}\right)$ & 43.827 & 45.564 & 48.294 & 52.086 & 52.722 & 52.996 & 48.605 \\
\hline Transformação $\left(10^{3} \mathrm{~m}^{3}\right)$ & 2.551 & 2.460 & 3.128 & 3.125 & 3.881 & 2.866 & 1.421 \\
\hline \multicolumn{8}{|l|}{ Biodiesel } \\
\hline Produção $\left(10^{3} \mathrm{~m}^{3}\right)$ & 2.397 & 2.673 & 2.717 & 2.917 & 3.420 & 3.937 & 3.801 \\
\hline Transformação $\left(10^{3} \mathrm{~m}^{3}\right)$ & 121 & 55 & 121 & 105 & 177 & 112 & 81 \\
\hline Álcool Anidro & & & & & & & \\
\hline Produção $\left(10^{3} \mathrm{~m}^{3}\right)$ & 8.357 & 9.050 & 9.564 & 12.005 & 12.230 & 11.565 & 11.727 \\
\hline Álcool Hidratado & & & & & & & \\
\hline Produção $\left(10^{3} \mathrm{~m}^{3}\right)$ & 19.567 & 13.866 & 13.913 & 15.603 & 16.296 & 18.685 & 16.549 \\
\hline $\begin{array}{l}\text { ENERGIA EÓLICA } \\
\text { Geração Total (GWh) }\end{array}$ & 2.177 & 2.705 & 5.050 & 6.576 & 12.210 & 21.626 & 33.489 \\
\hline
\end{tabular}




\section{$3.7 \quad 2016$}

Com exceção do Álcool Anidro, a produção dos demais biocombustíveis teve uma queda em 2016 [20].

Outro grande salto se deu em 2016 no que se refere a produção de energia eólica, passando, neste ano, a 33.489 GWh [20].

O maior salto em capacidade de energia solar aconteceu em 2016, quando passou a ter 80 MW, com 7.437 usinas [21].

Para uma visualização geral de toda a evolução produtiva destes anos, faz-se necessário a tabela acima.

Para uma melhor visualização da evolução da capacidade energética da fonte solar neste período, segue uma tabela:

\begin{tabular}{lrrrrrrr}
\hline Ano & 2010 & 2011 & 2012 & 2013 & 2014 & 2015 & 2016 \\
\hline Capac. & 20 & 1 & 8 & 5 & 15 & 21 & 80 \\
Instalada & kW & MW & MW & MW & MW & MW & MW \\
\hline
\end{tabular}

Tabela 2: Evolução da Capacidade Instala-da de Energia Solar no Brasil de 2010 a 2016, elaboração própria a partir de dados dos Boletins Mensais do Sistema Elétrico Brasileiro dos anos de 2010 a 2016 [10] [14] [17] [19] [21]

\section{Fatores relacionados ao desenvolvimento de novas fontes de energias renováveis no Brasil de 2010 a 2016}

\subsection{Biocombustíveis}

A iniciativa governamental, lançada pelo Ministério de Minas e Energia, para a expansão da produção de biocombustíveis, é a chamada RenovaBio, parte integrante da Política Energética Nacional, visando contribuir para o sucesso dessa iniciativa, composta por ações, atividades, projetos e programas para viabilizar a oferta de energia de forma mais sustentável, competitiva e segura.
Para o seu desenvolvimento amplo e sustentável, é fundamental o incentivo à pesquisa e inovação relacionada aos biocombustíveis.

O Governo lançou, em 2011, o Plano Conjunto BNDES-Finep de Apoio à Inovação Tecnológica Industrial dos Setores Sucroenergético e Sucroquímico - PAISS, com foco comercial desenvolvido por empresas, visando fomentar iniciativas em Pesquisa e Desenvolvimento em temas específicos relacionados à conversão da biomassa da cana-de-açúcar em etanol de segunda geração [22].

Esta área também se beneficiou de apoio técnico e financiamento à atividade de Pesquisa e Desenvolvimento, através de pesquisas acadêmicas da Fundação de Amparo à Pesquisa do Estado de São Paulo (Fapesp), pelo Programa de Pesquisa em Bioenergia (Bioen).

Contudo, alguns entraves são presentes para que haja uma evolução consistente dos biocombustíveis no Brasil, os quais são [22]:

- A produção do etanol lignocelulósico ainda precisa solucionar problemas na etapa de prétratamento, o que permitiria o máximo de rendimento à nível industrial da produção, para então, avançar mais eficazmente nas demais etapas do processo de produção e atingir um preço mais competitivo.

- No caso do Óleo Vegetal Hidrotratado (biodiesel), além de não existir regulação específica para seu uso, a sua matéria prima tem alto valor agregado e o processo de conversão da sua matéria prima ainda é oneroso a tal ponto de não ser competitivo com relação aos combustíveis similares.

- Até o momento não há legislação específica dedicada aos novos biocombustíveis, o que se pressupõe que a carga tributária pode ser mais elevada, dificultando sua competitividade internacional.

\subsection{Eólica}

De 2010 a 2013 o crescimento da energia eólica foi relativamente lento e podemos verificar em 2014 o salto que deu com relação a estes três anos anteriores. O setor de energia eólica no Brasil vem criando incentivos para substituir as importações de aerogeradores e seus componentes pela produção http: / / dx.doi.org/10.25286/repa.v2i4.890 
nacional que são demandados para a construção dos parques [23].

O Proinfa, instituído em 2002, foi o principal motor para impulsionar o desenvolvimento do mercado eólico no Brasil. Como a primeira política pública efetiva voltada ao setor, proporcionou um ambiente com poucos riscos para o investimento em uma tecnologia ainda pouco conhecida no país. O programa mostrou que a energia eólica é viável tecnicamente, e serviu como ganho de experiência para as diversas atividades que envolvem esse setor. Ao final de 2011, já haviam cinco empresas fabricantes de aerogeradores no Brasil e o país era considerado o $9^{\circ}$ mais atrativo para investimento em energia eólica [24].

Em 2014, o benefício líquido eólico foi de $\mathrm{R} \$ 5.098$ milhões, pela economia de custo com despacho das usinas termelétricas de $\mathrm{R} \$ 7.687$ milhões e pela receita gerada da energia eólica em $\mathrm{R} \$ 2.598$ milhões. Sua contribuição também pode ser medida pela quantidade de lares brasileiros servidos por esta fonte ( 6 milhões de residências por mês) e pelo volume de emissão de gases de efeito estufa evitados pela produção de energia eólica em seis milhões de toneladas [25].

Nos anos seguintes, houve um aumento considerável na produção de energia eólica, como visto nos dados apresentados anteriormente. A tendência é aumentar ainda mais nos próximos anos. Mais facilidades de financiamento auxiliam a impulsão da produção eólica.

\subsection{Solar}

Em 2011 foi criada a lei no 12.431 que isenta rendimentos de pessoas físicas de Imposto de Renda sobre rendimentos relacionados à emissão de debêntures, entre os quais os destinados a geração de energia elétrica por fonte solar.

Em 2012 houve o Sistema de Compensação de energia elétrica para a micro e mini geração distribuídas, permitindo que consumidores com geração eólica de até $5 \mathrm{MW}$ compensem a energia injetada na rede com a energia consumida.

Começaram em 2014 os leilões de energia fotovoltaica, promovido pelo Ministério de Minas e Energia e pela Empresa de Pesquisa Energética, sendo responsáveis pela contratação de mais de $3 \mathrm{GW}$ de potência solar. Energias estas que sequer foram produzidas. A principal barreira para a energia solar é o seu alto custo de aquisição do sistema e também a falta de conhecimento de certos grupos sociais ao acesso a linhas de financiamento de baixo custo.

\section{Considerações Finais}

Cabe aqui algumas considerações relevantes para que haja uma melhor expansão da produção energética a partir das novas fontes renováveis no Brasil.

Para a expansão de biocombustíveis é necessário criar uma estrutura logística, que possibilite desenvolver as redes de coleta e distribuição. Cabe nesse contexto a participação não apenas da iniciativa pública como também o engajamento do setor privado, já que, é possível alguns usufruírem de matérias prima de baixo valor agregado, evitando dessa forma a descentralização de toda a cadeia produtiva.

A energia eólica é uma grande aliada das hidrelétricas, uma vez que sua energia produzida pode ser armazenada nas hidrelétricas, o que auxilia na geração de energia quando há redução do volume dos reservatórios.

Como barreiras há as questões da ordem política, econômica e tecnológica, como da necessidade de licença ambiental para instalação do parque eólico, a logística por via rodoviária e ferroviária no Brasil, que é deficiente, não favorece o transporte das grandes estruturas dos aerogeradores, dentre outras.

Há uma vantagem econômica tangível para o investimento e para aquisição de um sistema solar residencial. Os custos de energia solar também estão diminuindo.

A matéria prima para a geração de energia solar é um recurso abundante, acessível e barato no Brasil, o sol. Com os incentivos do governo em promover a geração de energia solar nas residências, o imóvel é valorizado e é palpável a economia que ela proporciona na conta de energia, diferente das tarifas de energia habituais que só aumentam.

Mais incentivos podem auxiliar na alavancada da produção de energia solar, como mais facilidade de investimento, possibilidade de se utilizar o FGTS para aquisição de sistemas solares, menos tributos e redução de ICMS para a energia gerada a partir da 
solar e além disto, a disseminação e educação sobre a tecnologia solar.

Dentre o que foi abordado, em todas as áreas, torna-se necessário o investimento contínuo em Pesquisa e Desenvolvimento, a fim de se obter um melhor aproveitamento dos recursos produtivos, tornando mais eficiente e eficaz a produção das energias e biocombustíveis. Isto resultará em um produto final com preços mais competitivos, havendo mais demanda, o que estimula a sua produção.

\section{Referências}

[1] Brasil. Ministério De Minas E Energia. Boletim Mensal de Monitoramento do Sistema Elétrico Brasileiro. Disponível em http://www.mme.gov.br/documents/1138781/14 35504/Boletim+de+Monitoramento+do+Sistema +El\%C3\%A9trico+-+Julho+-+2017.pdf/e84e3eee7239-4ff3-a306-afb269b1e393, Julho de 2017.

[2] L. Losekann, M. Hallack. Novas energias renováveis no Brasil: desafios e oportunidades. Dis-ponível em:

https://www.ambienteenergia.com.br/index.php/ 2017/06/novas-energias-renovaveis-brasil-desafiose-oportunidades/31794, 07 de Junho de 2017, acesso em 08 de Set. de 2017.

[3] J. C. Fernandez, R. Pereira. O Custo Social da Energia Hidrelétrica e uma Política de Tarifação Social Ótima para o Setor Elétrico. Revista Eco-nômica do Nordeste, Fortaleza, v. 39, no 4, out-dez. 2008, p. 480. Disponível em: https://www.bnb.gov.br/projwebren/Exec/artigo RenPDF.aspx?cd_artigo_ren=1108, 15 Set 2017.

[4] Veja. Custo de operação e manutenção de hidre-létrica é de $\mathrm{R} \$ 4$, diz Aneel. 14 Nov. 2012. Disponível em: http://veja.abril.com.br/economia/custode-operacao-e-manutencao-de-hidreletrica-e-de-r-4diz-aneel/, acesso em 11 de Set. de 2017

[5] Empresa de Pesquisa Energética (Brasil). Balan-ço Energético Nacional: Matriz Energética Nacional 2017 - Ano Base 2016. Disponível em: https://ben.epe.gov.br/downloads/MatrizEnergeti caBase2016.xlsx, acesso em 15 Out. 2017.EPE. RenovaBio: Biocombustíveis 2030. Minis-
[6] tério de Minas e Energia. Rio de Janeiro, 24 de fevereiro de 2017. Disponível em: http://www.mme.gov.br/web/guest/consultas-publicas?p_auth $=$ wN8rWKxx\&p_p_id=consultapubli caexterna_WAR_consultapublicaportlet\&p_p_lifecycle $=1 \& p \_p \_s t a t e=$ normal\&p_p_mode $=$ view $\&$ p_p_ col_id=column-

1\&p_p_col_count=1\&_consultapublicaexterna_ WAR_consultapublicaportlet_arquivoId $=120 \&$ _ consultapublicaexter-

na_WAR_consultapublicaportlet_javax.portlet.a ction=downloadArquivoAnexo, acesso em: 09 Set. 2017.

[7] Empresa De Pesquisa Energética (Brasil). Balanço Energético Nacional 2011: Ano base 2010 / Empresa de Pesquisa Energética. - Rio de Janeiro : EPE, 2011.

[8] Ministério De Minas E Energia. Monitoramento do Sistema Elétrico Brasileiro. Boletim de Janeiro/2010, p. 20 . Disponível em: http://www.mme.gov.br/documents/10584/1832 844/Boletim_Monitoramento_Sistema_Elxtrico_ Jan_10.doc/cbbf0330-84dd-4fbb-938e87d1d8cc922a, 12 Set. 2017.

[9] Brasil. Empresa de Pesquisa Energética. Balanço Energético Nacional 2012 - Ano base 2011: Síntese do Relatório Final. Rio de Janeiro: EPE, 2012.

[10] Ministério De Minas E Energia. Boletim Mensal de Monitoramento do Sistema Elétrico BrasileiroJaneiro/2011, p. 22. Disponível em: http://www.mme.gov.br/documents/10584/1832 384/Boletim_de_Monitoramento_do_Sistema_El xtrico_-_JANEIRO-2011.doc/99bee702-007f-472f9c53-6241229bb69b, acesso em 14 Set. 2017.

[11] Ministério De Minas E Energia. Boletim Mensal de Monitoramento do Sistema Elétrico BrasileiroJaneiro/2011, p. 22 . Disponível em: http://www.mme.gov.br/documents/10584/1832384 /Boletim_de_Monitoramento_do_Sistema_El xtrico__JANEIRO-2011.doc/99bee702-007f-472f-9c536241229bb69b, acesso em 14 Set. 2017.

[12] Ministério De Minas E Energia. Boletim Mensal de Monitoramento do Sistema Elétrico Brasileiro- Dezembro/2012, p. 30. Disponível em: http://www.mme.gov.br/documents/10584/1832 054/Boletim_de_Monitoramento_do_Sistema_El xtrico_-_Dezembro2_-2012.doc/373ffb0c-9c904ae4-af0c-5a3866bdb718, acesso em 14 Set. 2017. http: / / dx.doi.org/10.25286/repa.v2i4.890 
[13] Ministério De Minas E Energia. Boletim Mensal de Monitoramento do Sistema Elétrico Brasileiro- Janeiro/2012. Disponível em: http://www.mme.gov.br/documents/10584/1832 054/Boletim_de_Monitoramento_do_Sistema_El xtrico_-_JANEIRO-2012.doc/e79c415f-722c-442b8d54-b83f1fa1cfdd, acesso em 14 Set. 2017.

[14] Ministério De Minas E Energia. Boletim Mensal de Monitoramento do Sistema Elétrico Brasileiro- Dezembro/2012. Disponível em: http://www.mme.gov.br/documents/10584/1832 054/Boletim_de_Monitoramento_do_Sistema_EI xtrico_-_Dezembro2_-2012.doc/373ffb0c-9c904ae4-af0c-5a3866bdb718, acesso em 14 Set. 2017.

[15] Empresa de Pesquisa Energética (Brasil). Balan-ço Energético Nacional 2013: Ano base 2012 / Empresa de Pesquisa Energética. - Rio de Janei-ro: EPE, 2013. Disponível em: https://ben.epe.gov.br/downloads/Relatorio_Fina I_BEN_2013.pdf, acesso em 15 Set. 2017.

[16] Empresa de Pesquisa Energética (Brasil). Balan-ço Energético Nacional 2014: Ano base 2013 / Empresa de Pesquisa Energética. - Rio de Janei-ro : EPE, 2014. Disponível em: https://ben.epe.gov.br/downloads/Relatorio_Fina I_BEN_2014.pdf, acesso em 15 Set. 2017.

[17] Ministério De Minas E Energia. Boletim Mensal de Monitoramento do Sistema Elétrico Brasileiro- Dezembro/2013. Disponível em: http://www.mme.gov.br/documents/10584/1831 421/Boletim_de_Monitoramento_do_Sistema_El xtrico_-_Dezembro-2013.pdf/f1bf83d8-337a-435d8adc-661992b299b7, acesso em 14 Set. 2017.

[18] Empresa de Pesquisa Energética (Brasil). Balan-ço Energético Nacional 2015: Ano base 2014 / Empresa de Pesquisa Energética. - Rio de Janei-ro : EPE, 2015. Disponível em:https://ben.epe.gov.br/downloads/Relatorio_Fina I_BEN_2015.pdf, acesso em 15 Set. 2017

[19] Ministério de Minas e Energia. Boletim Mensal de Monitoramento do Sistema Elétrico Brasileiro - Dezembro/2014. Disponível http://www.mme.gov.br/documents/10584/1833441 /Boletim+de+Monitoramento+do+Sistema+El\%C3\% A9trico+-+Dezembro-2014+-+rev1.docx/df8bccee8423-40b6-af58-311ff9ae6ae4, acesso em 15 Set. 2017.
[20] Empresa de Pesquisa Energética (Brasil). Balan-ço Energético Nacional 2017: Ano base 2016 / Empresa de Pesquisa Energética. - Rio de Janei-ro : EPE, 2017. Disponível em: https://ben.epe.gov.br/downloads/Relatorio_Fina I_BEN_2017.pdf, acesso em 15 Out. 2017.

[21] Ministério de Minas e Energia. Boletim Mensal de Monitoramento do Sistema Elétrico Brasileiro - Dezembro/2016. Disponível em: http://www.mme.gov.br/documents/10584/3308 684/Boletim+de+Monitoramento+do+Sistema+ El\%EF\%BF\%BDtrico+-+Dezembro2016.pdf/f6b5284d-4105-4b79-a03031755664721 a, acesso em 15 Out. 2017.

[22] EPE. RenovaBio: Biocombustíveis 2030. Minis-tério de Minas e Energia. Rio de Janeiro, 24 de fevereiro de 2017. Disponível em: http://www.mme.gov.br/web/guest/consultas-publicas?p_auth=wN8rWKxx\&p_p_id=consultapubli caexter-

na_WAR_consultapublicaportlet\&p_p_lifecycle $=1 \& p \_p \_s t a t e=$ normal\&p_p_mode $=$ view $\&$ p_p_ col_id=column-

1\&p_p_col_count $=1 \&$ _consultapublicaexterna_ WAR_consultapublicaportlet_arquivoId $=120 \&$ _ consultapublicaexter-

na_WAR_consultapublicaportlet_javax.portlet.a ction=downloadArquivoAnexo, acesso em: 09 Set. 2017.

[23] D. Mori. Desenvolvimento da Energia Eólica no Brasil estimula indústria nacional. Política Industrial. Jornal GGN, 2014. Disponível em: http://jornalggn.com.br/noticia/desenvolvimento-daenergia-eolica-no-brasil-estimula-industria-nacional, acesso em 18 Set. 2017.

[24] M. Simas, S. Pacca. Energia eólica, geração de empregos e desenvolvimento sustentável. Estud. av. vol.27 no.77 São Paulo, 2013. Disponível em: ttp://www.scielo.br/scielo.php?script=sci_arttex t\&pid=S0103-40142013000100008, acesso em 18 Set. 2017.

[25] Abeeólica. Boletim Anual de Geração Eólica. Associação Brasileira de Energia Eólica. 2014. Disponível em: http://www.abeeolica.org.br/wpcontent/uploads/2016/08/Boletim-Anual-deGeracao-Eolica-2014.pdf, acesso em 19 Set.2017. 